PHILOSCPHIA DO DIREITO

\title{
HA UM DIREITO NATURAL?
}

\begin{abstract}
«On est si généralement mécontent des théories existantes en matiére de droit, et si généralement convaincu qu'elles ne résolvent pas les questions qu'elles prétendent résoudre, qu'on peut soupconner qu'une branche de recherches nécessaires pour obtenir un résultat complet a été négligée ou entierment oubliée par les auteurs de ces théories (Sumner Maine, "L'Ancien Droit," pag. 112 da trad. de Courcelle Seneuil)»
\end{abstract}

A reacção contra os processos aprioristicos applicados ao estudo da philosophia do direito, e o empirismo com que têm empregado o methodo positivo juristas que não se elevam ás ultimas generalisações da sciencia, têm gerado em alguns espiritos contemporaneos a convicção de que nào ha um direito natural, isto é, um conjuncto de principios juridicos, fundamentaes, anteriores e superiores á legislação escripta, necessarios e peculiares ao organismo social, quaesquer que sejam o ponto do espaço e o momento do tempo em que elle exista.

Em face da escóla theologica, ou da escóla racionalista, nada mais fundado que essa convicção.

Para a primeira dessas escólas o direito natural é, $\mathrm{cm}$ synthese, um conjuncto de principios juridicos 
fundamentaes, derivados da natureza humana, e transmittidos á nossa intelligencia por uma revelação sobrenatural. Ora, a negação do sobrenatural é um resultado ineluctavel do progresso das sciencias modernas.

Não mais é permittido ao homem de sciencia architectar suas doutrinas sobre conceitos que não nos sejam dados, directa ou indirectamente, inductiva ou deductivamente, pela observação e pela experiencia. Subir pela inducção, por um processo de generalisação, gradual e crescente, ás leis mais geraes, aos principios fundamentaes da sciencia, e desses principios deduzir syllogisticamente as verdades que elles encerram, - eis o unico methodo logico, scientifico, qual. quer que seja o objecto de nossas investigações.

Dogmas, pontos de fé, crenças individuaes, não ministram base para deducções scientificas. "Si eu habituo meus filhos á crença de que o bem e o mal consistem naquillo que agrada ou desagradia a Jupiter, no dia em que a existencia de Jupiter não lhes parecer demonstrada, elles acreditarão que não ha mais bem, nem mal. Ora, quem póde demonstrar mathematicamente a existencia de Jupiter? Todas as mythologias têm um lado vulneravel; todas as metaphysicas offerecem um flanco ao scepticismo; procuremos uma theoria moral que se funde, como a geometria, sobre principios independentes, pois que a moral, como a geometria, deve ser conhecida e applicada por todos os homens sem excepção $(*)$ ». Ao direito ainda mais que á moral é applicavel esse raciocinio infrangivel.

A escóla theolngica, em summa, não emprega os processos scientificos para descubrir e formular as normas juridicas; não estuda as relações entre os actos voluntarios do homem e suas consequencias proximas e remotas para o individuo, para a sociedade e para

(*) Thirion, Norale et Religion -- pag. 175. 
a humanidade: despreza as connexões causaes ultimas, e architecta toda a sua doutrina sobre pontos de fé, sobre principios acceitos unicamente pelo circulo, cada dia mais estreito, dos espiritos crentes. Não demonstra scientificamente a existencia de um direito natural.

Para os adeptos da escóla racionalista o direito natural é, em synthese, um conjuncto de principios juridicos, fundamentaes, concebidos pela razão. Ora, a razão para essa escobla é uma faculdade de intuição, que nos communica immediatamente, sem dependencia de raciocinios, as ideias absolutas do bem, do bello, do verdadeiro e do justo. Basta-nos essa noção, hoje repellida pelos mais eminentes mestres da psychologia e da logica, que nos ensinam e irrefragavelmente demonstram que todos esses principios e conceitos fundamentaes da mente humana são resultados de inducções, -basta-nos essa noção para nos convencermos da especiosa inanidade das theorias racionalistas.

De facto, a psychologia comparada é irrefutavel, quando nos mostra que em certas hordas selvagens não se descobre pela mais minuciosa perquisiçâo a mais vaga noção do justo: a força material não é contrastada por nenhuma ideia de lei juridica.

E' verdade que os philosophos e jurisconsultos subjectivistas procuram refutar esse argumento, ponderando que a razão apenas communica os principios absolutos á intelligencia do homem, que póde comprehendel-os, e realmente comprehende-os, de modos diversos, com interpretações varias.

Mas, em que nos aproveitaria ministrar a rasão o principio absoluto, universal e eterno do justo, si na apreciação dos actos que mais interessam á existencia e ao desenvolvimento do individuo e da sociedade, elle não nos fornece um criterio seguro e constante, $\mathrm{e}$ é susceptivel das mais contrarias e estolidas appli. cações? 
O principio do justo não é, não póde ser, transmittido á intelligencia do homem por uma intuição immediata: esse principio é apprehendido discursiva, e não intuitivamente.

Nas agremiações primitivas, nas sociedades embryonarias, lucta cada individuo, impellido pelo instincto de conservação e por seus sentimentos egoisticos, pela posse e conservação das cousas que lhe são necessarias, e para evitar a dôr e augmentar os estados agradaveis do sentimento. A vida, a integridade physica, a propriedade, a liberdade civil, todos esses inestimaveis bens, mais tarde garantidos pela norma juridica, nessas rudes épochas primitivas só encontram defesa na força physica individual, na energia e no egoismo de cada um.

E' este mesmo egoismo que pouco a pouco vai cohibindo a pratica dos actos contrarios ao interesse da collectividade, á proporção que se vai comprehendendo a estreita connexão que ha entre os interesses do individuo e os da agremiação.

Lentamente vão-se firmando normas a que se subordinam os actos voluntarios do homem que são condições de vida e progresso para o individuo e para a sociedade, e assim se formula a lei juridica.

Isto posto, é justo o acto voluntario cujas consequencias não perturbam a existencia e o aperfeiçoamento do individuo, ou da sociedade, sem a qual não se comprehende o homem.

Vê-se, pois, que, para apreciarmos a justiça de um acto, precisamos de previamente approximar desse acto as suas consequencias directas e indirectas, proximas e remotas, e verificar si elle tende a destruir o equilibrio social, a vida ou a aperfeiçoamento do individuo: é necessario, em ultima analyse, que formemos uma serie de juizos. 
O principio do justo, recondito na razão do homem, em estado potencial ou virtual, sem relação com os actos voluntarios que praticaınos, é uma abstracçàn que a mente humana não comprehende.

Mas, objecta-se, mesmo entre os selvagens os actos praticados voluntariamente pelos homens são approvados ou reprovados, são reputados bons ou máos. Grosseira confusão de ideias! Entre as hordas cannibaes esses actos são apreciados com o criterio da utilidade, e não da justiça, do prazer, ou da dôr, e não do direito e da moral.

A escola racionalista, em summa, despreza os dados da observação, os ensinamentos da psychologia comparada e da ethnologia, e toma como ponto de partida conceitos pelo menos contestados com bons fundamento pelos mais eminentes pensadores, pelos Stuart Mill, pelos Spencer, Bain e tantos outros.

Seguir-se-ha do que temos dito que não ha um direito natural?

Para respondermos a pergunta, é mister que tenhamos uma ideia exacta da lei em geral, e especialmente da lei moral.

\section{Que é lei?}

Segundo a noção classica de Montesquieu, as leis são as relações necessarias que derivam da natureza das cousas. Para A. Cornte - as leis são as relações constantes de successão e semelhança entre os phenomenos, relaçôes que nos permittem por alguns desses phenomenos prevêr os outros. As leis são as relações uniformes de successão e simultaneidade, resumio Stuart Mill. A lei é a ordem regular com a qual se conformam as manifestações de uma força, ou de un poder, - eis a formula de Spencer. 
As ideias contidas em todas essas noções foram clara e concisamente concretisadas por Bertrand, em seu moderno Lexicon de Philosophia, nas seguintes palavras: as leis são as relações constantes e invariaveis que ligam os phenomenos.

Si limitamos nossas investigações ao mundo inorganico, facil é comprehender as connexões necessarias, fataes, que ahi se observam: ao attentarmos no movimento uniforme dos astros, na queda constante sobre a terra dos corpos mais pezados que o ar ambiente, na successão tão regular das estações, dos dias e noites, adquirimos a convicção de que ha na realisação desses phenomenos um encadeamento de causas e effeitos, de que deriva a necessincde de que taes resultados se produzam. $\mathrm{Na}$ lei da gravitação universal, segundo a qual todos os astros, em todos os pontos do espaço e do tempo, se attrahem na razão directa das massas e na inversa do quadrado das distancias, apprehende-se claramente o que é a relação constante e invariavel que se denomina lei.

Será essa noçâo de lei applicavel a todos os phenomenos, - do mundo inorganico, organico e superorganico, ou social? Por outras palavras, restringindo a pergunta, e dirigindo-a especialmente para o fim que temos em mente, - terá a lei moral por conteúdo relações constantes e invariaveis, como a lei physica?

Ensina a mais rudimentar observação que, d'entre os actos voluntarios praticados pelo homem, alguns concorrem para a conservação e aperfeiçoamente do individuo, ou da sociedade, que é o mejo necessario dentro do qual é possivel ao individuo viver, desen. volvendo-se; outros, pelo contrario, produzem o desequilibrio social, perturbam a existencia e o progresso do individuo. Essas relações entre os actos voluntarios 
do homem e suas consequencias são constantes, neces. sarias, estabelecidas pela natureza das cousas.

Arvore-se em norina de conducta o homicidio, o roubo, as offensas physicas, e a sociedade fatalmente perecerá.

Observados e coinparados os factos, approximadas destes as suas naturaes consequencias, a intelligencia logicamente induz, generalisa, apprehende as leis a que os phenomenos moraes estão subordinados.

Essas leis têm uma sancção natural: as consequencias bôas, ou más, que fatalmente decorrem dos actos voluntarios por nós praticados.

Uma vez conhecida a sancção natural, e compre. hendida a necessidade de observar a lei moral, o instincto de conservação, a tendencia do homem para o que elle reconbece ser um bem, todos os scus sentimentos individuaes e sociaes, em summa, o impellem e adstringem á pratica dos actos conformes ás uormas descobertas e formuladas.

Attingido certo gráu de desenvolvimento intellectual e moral, a comprehensão da sancção natural produz necessariamente a approvaçâo, ou reprovaçào, da cousciencia para os factos do dominio da ethica (sancção moralj, a approvação, ou reprovaçào, da sociedade (sancção social) e o temor das penas, ou esperança das recompensas na vida de além tumulo (sancção religiosa).

D'entre as leis de ordem moral destaca se um conjuncto de normas que regulam as relações dos individuos entre si, ou com a collectividade, e ás quaes, pela relevancia das condições de vida e progresso que garantem, é adjectivada uma nova especie de sancção, - a coacção physica, o emprego da forçáa nos casos necessarios. Scinde-se a ethica em lous ramos distinctos de normas: - a moral no sentido stricto do termo e o direito. 
Isto posto, as forças propulsoras da nossa actividade moral são os dous factores fundamentaes do nosso dynamismo psychico, - a ideia e o sentimento, o couhecimento da lei cuja observancia conduz ao bem, e a tendencia, o impulso da sensibilidade moral para a realisação dos actos conformes a essa lei, ou o temor das consequencias penosas que derivam do facto de infringil-a.

Como actúam essas forças? Só poderemos sabel-o, estudando o mechanismo da nossa vontade.

De um dos mais admiraveis estudos que se têm feito sobre essa faculdade, o "Ensaio sobre o livre arbitrio", de Schopenhauer, extrahiremos, resumindo as noções que mais nos importa conhecer a respeito.

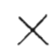

O principio de causalidade, que rege todas as modificações dos seres, manifesta-se sob tres aspectos: - causalidade no sentido stricto, ou causação, excitação e motivação.

A causação domina as transformações dos corpos inorganicos; a excitação as dos seres do reino vegetal c dos animaes cuja intelligencia não attinge certo gráo de desenvolvirnento; a motivação é o principio de causalidade applicado aos phenomenos que sâo produzidos pela vontade propulsada pelo pensamento e pelo seutimento.

Em todas essas manifestações do principio de causalidade ha uma força irresistivel, impera soberanamente a necessidade.

No mundo inorganico essa necessidade é evidente, e facilmeute impõe-se an nosso espirito, em virtude da simplicidade que caracterisa os phenomenos dessa ordem. 
O gráo de intensidade do effeito está em proporção exacta com o gráo de intensidade da causa: o corpo que transmitte um impulso perde uma quantidade de força egual á que communica ao corpo antes immovel. Observa-se o facto invariavelmente em todas as transformações mechanicas. Mas, á proporção-que se vai subindo a escala dos seres, na ordem crescente de sua complexidade, a causa e o effeito vão-se differençando gradativamente, e torna-se cada vez mais difficil apprehıender o laço que vincúla o consequente ao antecedente.

$\mathrm{Na}$ segunda fórma da causalidade, a excitação, não ha proporcionalidade exacta entre a acção e a reacção correspondente. A iufluencia do calôr póde activar extraordinariamente o crescimento das plantas; mas, ultrapassada certa medida, aquelle estimulante da força vital produz não o augmento de actividade e a maturidade precoce, mas a morte do vegetal.

Finalmente, na mais complexa das fórmas da causalidade, na motivação, as forças externas que actúam sobre a nossa vontade, como propulsores, atravessam o cadinho de nosso espirito, onde se transformam em ideias e sentimentos, cuja energia depende da recentividade da vontade. Ora, esta receptividade, a constituição psychica de cada individuo, a natureza e as tendencias de cada espirito, estão subordinadas á influencia dos elementos physiologicos e ethnologicos, da educação, da instrucção, de um numero illimitado de circumstancias. Dahi a difficuldade, senão impossibilidade, de, com os nossus limitados e deficientes meios de conhecer, prevêr a proporcionalidade entre a acção dos motivos e a reacção do espirito, entre a causa e o effeito.

Uma verdade geral, porém, paira acima de quaesquer discussões: a vontade $e$ fatalmente impellida pelos motivos; dado o conflicto entre motivos diversos, 
aquelle que relativamente é mais poderoso necessariamente prevalece, e determina as nossas resoluções. Dizemos relativamente, porque a energia dos motivos não é intrinseca, objectiva, mas depende da receptividade de cada espirito: aquillo que para um homem civilisado e de coração bem formado é um motivó preponderante póde não passar de um motivo secundario, on absolutamente nullo, para um cerebro rude, dominado pelas tendencias e necessidades physiolologicas inferiores, communs a toda a escala zoologica.

Isto posto, temos que a vontade não é livre, mas fatalmente determinada.

Duas provas irrefragaveis nos convencem dessa verdade: $1 .^{a}$ o testemunho de nossa consciencia: $2 .^{a}$ a convicção profunda da humanidade, convicção manifestada pelos seus orgãos mais autorisados, por todos os legisladores, por todos os moralistas e jurisconsultos, e que se externa a cada momento nos actos da vida pratica.

Por mais paradoxaes que se affigurem essas duas asserções aos espiritos imbuidos das ideias dominantes sobre o livre arbitrio, cllas não deixam de ser a expressão exacta da realidade.

A consciencia nos attesta exactamente o contrario. - que podemos fazer o que queremos, objectam com ares triumphaes os adversarios do determinismo. Manifesta confusão de ideias! Confunde-se a liberdade dos actos com a liberdade das volições! Que, tomada uma resolução, nós podemos pól-a em pratica, realisar o acto resolvido, querido, - eis uma verdade indiscutivel para todo o homem sensato.

Mas, - não desloquemos a qucistão, - não se trata de saber si queremos o que fazemos, que é o que se denomina a liberdade physica; o que cumpre é investigar si nós queremos as nossas volicões. Cada indi. viduo faz aquillo que quer, desde que não se lhe 
depare um obstaculo externo: mas, cada individuo quer o que quer? Esse é o problema a resolver.

Quando temos de realisar um acto importante de nossa vida, de resolver sobre o futuro nosso, ou dos entes que nos são caros, o determinismo psychologico patenteia-se de modo a impôr-se a todo o espirito despido de preconceitos. Deliberar é pesar os motivos, assistir á lucta travada entre as forças contrarias que disputam a nossa vontade, para acceitar irremissivelmente o jugo da que sahe victoriosa do conflicto. Quanto mais isento fôr o animo daquelle que se resolve, quanto mais vasio de preconceitos, de elementos subjectivos, que perturbem a nitida visão da realidade externa, tanto mais acertada será a resolução. Acceitar este, ou aquelle motivo, como preponderante, é um acto que depende do desenvolvimento da intelligencia de cada individuo, de sua educação e elevação moral, de seu temperamento, de varios outros factores, que de modo algum têm como causa efficiente a nossa vontade.

Assim, quando deliberamos, nossa intelligencia nada mais faz que investigar qual o motivo mais forte, e, uma vez feita essa averiguação, a intelligencia e $o$ sentimento arrastam fatalmente a vontade a submetter-se ao motivo victorioso.

Incontestavel, de uma evidencia indiscutivel, em todos os actos volitivos que são precedidos de longas deliberações, de meditação demorada, o facto assignalado, por ser de menos facil percepção, não deixa de verificar-se em todas as demais resoluções.

Uma illusão dia consciencia, muito commum, parece oppôr-se a essa verdade: do facto de podermos pensur (note-se bem) na realisação de duas acções inteiramente oppostas tiramos a conclusão de que em um caso determinado nos é possivel querer egualmente dous actos contrarios. E' olvidar completamente 
as circumstancias especiaes que em cada hypothese dada rodêam as nossas volições.

Schopenhauer desfaz essa illusão por meio desta bella e significativa prosopopeia:- Eu poderia, diz a agua, levantar-me ruidosamente em vagalhões immensos, tragando navios alterosos, açoitando os mais elevados rochedos. - Sim, responde o philosopho, si fosse agua do mar, agitada por violenta tempestade. - Eu poderia precipitar-me em uma carreira vertiginosa, arrastando na minha passagem troncos de arvores, blocos de granito, cadaveres de homens. - Sim, poderia tudo isso, si fosse uma grossa torrente, que se despenhasse de alcantilada montanha.-Eu poderia esparzir-me pela atmosphera em ligeiros flocos niveos, tão brilhantes como os raios do sol.-Poderia, si fosse repuxo de jardim, em um dia de céo anilado, sob os reverbéros de um sol vivamente fulgurante. - Eu poderia reflectir com a maior nitidez as mais puras fórmas, os contornos das imagens mais bellas.-Sim, si fosse agua de lago, pura e crystallina, não encrespada a face pela mais ligeira brisa.

Não é só a consciencia que nos attesta que somos fatalmente vencidos pelos motivos.

O determinismo psychologico, consciente on inconscientemente, é de facto a theoria acceita por todos os legisladores, moralistas e jurisconsultas.

Todas as leis têm por base a presumpção de que a nossa vontade está sujeita á coacção des motivos. Que é um codigo penal, senão um conjuncto de motivos creados pelo legislador para o fim de superar os moveis e motivos possiveis que impellem o homem á perpetração do crime?

Não sendo a sancção natural facilmente perceptivel para a intelligencia de todos os individuos, e estando os proprios espiritos dotados da mais elevada cultura intellectual e moral sujeitos á contingencia de se deixarem 
dominar pelos mais baixos moveis e pelos motivos mais condemnaveis, o legislador crêa artificialmente uma serie de motivos facilmente comprehensiveis, adaptados ao gráo de intelligencia da generalidade dos homens, um certo numero de penas, por exemplo, de applicação immediata.

A' saneção natural addiciona-se esta sancção facticia.

Todos os systemas de moral repousam egualmente sobre o determinismo psychologico.

A moral theologica parte da theoria scientifica da motivação, pois que toda ella é architectada sobre a crença das penas e recompensas eternas; a moral racionalista assenta sobre a felicidade, ou o remorso, que se segue á pratica dos actos de ordem ethica; e a moral utilitaria sobre a utilidade immediata, do individuo ou da collectividade.

Tão incoercivel é a força da verdade, que nos actos mais triviaes da vida pratica, quotidianamente, a cada momento, nós externamos a nossa crença profunda no determinismo psycholngico.

- Com que fim prohibem os paes e educadores que as creanças a seu cargo presencêem actos deshonestos, e frequentem más companhia, ao passo que se esforçam por lhes incutir idéas de bem e de justiça? Si é verdadeiro o livre arbitrio, todo esse trabalho será vão; de nada serve indicar ás creanças o que devem fazer, ou evitar, porque nenhuma influencia terá em acto algum de sua vida o que lhes ensinaram, visto que a sua vontade não obedece a motivos de qualidade alguma. Desconfiar de todos é ao que logicamente nos leva a theoria do livre arbitrio; nâo podemos confiar no auxilio dos nossos concidadãos para continuar a obra do progresso, não podemos ter segurança em caracter algum, e dentro da nossa propria casa é preciso desconfiar de paes, irmãos e de todos os parentes, pois que, de um momento para outro, a vontade 
arbitraria de toda esta gente póde querer a nossa destruição. Que garantias nos dá o livre arbitrio de que tal não succederá? Os bons sentimentos d'essas pessoas, o seu comportamento?

Não, porque nem sentimentos, nem comportamento pódem influir na vontade, si ella se resolve sem condições, livre de todo o motivo (*),

De tudo o que temos escripto duas verdades se inferem: $1 .^{a}$ a nossa intelligencia descobre as leis moraes, auxiliada pelos mesmos processos logicos que applica ao estudo das leis physicas, a observação, a comparação, a abstracção, a inducção e a deducção; 2 . $^{\mathrm{a}}$ no desdobramento dos phenomenos moraes, assim como na producção dos phenomenos de ordem inorganica, impera a necessidade, distinguindo-se os primeiros phenomenos dos ultimos unicamente por sua extrema complexidade.

Resta-nos verificar si em meio das normas ethicas assignaladas ha algumas que revistam os caracteres connotativos do direito natural, segunda a noção que deste demos.

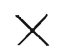

Exaggerada, como toda a escóla incipiente, dominada pelo enthusiasmo peculiar aos proselytos, a escóla naturalista não duvidou affirmar que fóra do dominio das leis positivas nada mais ha que necessidades bio-ethicas.

Mas, necessidades que são sempre as mesmas, condições de viảa indispensaveis, imposições fataes da natureza do individuo e da natureza da sociedade, imposições que, não satisfeitas, acarretam sempre e necessariamente os mesmos males, o perecimento, ou, pelo

(*) B. Lucas - A Loucura perante a Lei Penal, pag. 15. 
menos, o estacionamento da sociedade, e consequentemente do individuo, não constituirão o que scientificamente se denomina uma lei?

Essas necessidades estão sujeitas a leis, cuja sancção natural é mil vezes mais grave que a sancção creada pelos homens, e é justamente para evitar os terriveis e irreparaveis effeitos da sancção natural que se crêa a sancção facticia.

Herbert Spencer, em seu livro a "Justiça", para mostrar a necessidade deste principio organico de toda sociedade que se chama-direito, parte do estudo dos animaes gregarios, como, por exemplo, o castor. Depois de provar que todos esses animaes são levados, como o homem, á existencia gregaria, ou collectiva, pelo instincto de conservação, observa que, sendo os actos necessarios á alimentação de cada individuo realisados na presença de outros individuos que têm necessidades identicas, d'ahi resulta uma natural tendencia para constantes usurpações e esbulhamentos reciprocos. Si essas usurpações e violencias continúam, a associação deixa de existir.

E' necessario que cada membro do grupo, promovendo sua subsistencia e a de sua prole, não embarace os actos identicos dos consociados. Os soffrimentos que resultam da violação dessas restrições vão pouco a pouco disciplinando todos os membros do grupo. Assim, é impossivel ao homem a existencia social, á qual o impelle e adstringe sua natureza, sem a delimitação em torno de cada individuo da esphera dentro da qual elle póde agir, isto é, sem a observancia de certas normas.

Essas normas não têm todas o mesmo caracter de universalidade, de permanencia, de necessidade. Algumas regulam a satisfação de necessidades de ordem biologica, outras - necessidades transitorias creadas pela civilisação, determinadas pelo progresso das industrias, 
pelos habitos do luxo, pelas condições especiaes do commercio em um dado periodo, por $\mathrm{nm}$ sem numero de factores, que se alteram, que apparecem e supprimem-se no evolver das sociedades. Foram as modernas condições economicas que determinaram o apparecimento desta instituição juridica,-a sociedade anonyma, creação economico-juridica exigida pelas grandes emprezas que demandam capitaes consideraveis, ou são de resultados arríscados. Não se comprehende semelhante instituição em Roma, onde os grandes trabalhos de interesse geral, como a abertura de estradas, de portos, eram feitos pelos soldados em tempo de paz, sob a immediata direcção do Fistado.

As normas juridicas desta especie constituem a parte variavel do direito de um povo.

Mas, em meio da serie infinita de costumes, de leis, de instituições, por que se tem regido as sociedades nos differentes pontos do espaço e nos diversos momentos de tempo, ha um quid invariavel, um sub. stractum de principios necessarios, permanentes, universaes.

E' impossivel a existencia de uma agremiaçâo humana sem normas que, de qualquer modo, regulem a propriedade, a prestação de serviços por contractos, a união do homem com a mulher, a transmissão de bens dos mortos aos sobreviventes.

Esses principios fundamentaes, especificos do organismo social, troncos sobre os quaes se enxertam as mais variaủas instituições juridicas, constituem o direito natural.

A ethnologia nos ensina, póde-se objectar, que em certas hordas de selvagens nem sequer esses principios são observados. Não contestamos o facto. Responderemos apenas que essas rudes agremiações egualmente ignoram e transgridem as mais elementares leis da hygiene. E que homem sensato d'ahi tirará a 
conclusão de que essas leis não existam ou não devam ser observadas?

O cortejo de males que fatalmente decorre das infracções de uma e de outra especie de leis, clara e efficazmente nos attesta a existencia indiscutivel dessas leis. Sob esse aspecto, o direito natural é perfeitamente comparavel á hygiene.

As agremiações humanas que não se disciplinam juridicamente, sob o impulso do instincto de conservação, estão fatalmente votadas á decadencia, á desaggregação, á completa extincção.

S. Paulo, agosto de 1894.

Dr. Pedro Lessa. 